\title{
How to Walk on Water and Climb up Walls: Animal Movement and the Robots of the Future
}

By David L. Hu. 2018. Princeton University Press. 240 pages, 24.95 USD, Cloth or E-book.

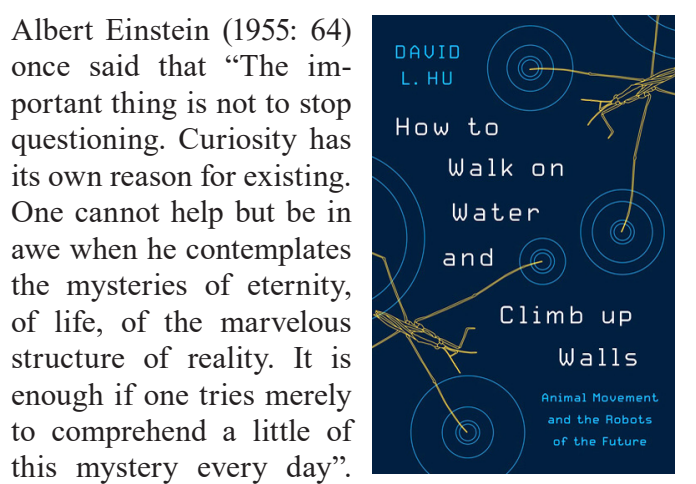

One can keep thinking about curiosity towards all aspects of life while reading How to Walk on Water and Climb up Walls: Animal Movement and the Robots of the Future.

In his book, David L. Hu, an associate professor of mechanical engineering and biology and adjunct professor of physics at Georgia Institute of Technology, tells us about his research and through that teaches us how to maintain curiosity and approach research questions. Specifically, in his research he tries to find and focus on the principles of animals' movements and apply these to robots. However, the book does not cover all animal motions, but generally those on which the author has done experimentations. For example, in the first chapter he shows us how the water strider's motion and ability to stand on water has inspired a water-walking robot. And in the second chapter we learn about the principles of crawling animals' (snakes and sandfish) movements. Next, Hu tells us about animals (e.g., jellyfish) that use their body parts to influence the flow of fluids for their own advantage. We learn about surface structure of animal bodies such as sharkskin (Chapter 4), and body structures (Chapter 5) that could be used to develop machines that are capable of moving underwater or on land with decreased energy expenditure or to design wearable devices - exoskeletons - that could lower the energy costs of human walking.

In the sixth chapter we learn how insects deal with collisions and how engineers are inspired by these insects as potential applications to robots. For example, how mosquitoes survive being struck by raindrops, bees survive crashing into obstacles such as flowers and plants, and cockroaches squeeze themselves into very narrow spaces. Then the author tells us how animals automatically respond to their surroundings, using the examples of flies overcoming turbulence during their flight and the cockroach's ability to measure its distance from the obstacles during quick running (Chapter 7). Finally, we learn about ants' ability to link their bodies to create a flow like liquid, form bridges, or spring back like a solid.

How to Walk on Water and Climb up Walls is interesting for those curious minds learning how one can do experimentation, as throughout the book $\mathrm{Hu}$ details the steps of his experiments and how he has overcome the problems during the process of experimentation. This book is for general readers interested in scientific inquiries as it teaches the way one should pursue them. It is full of colourful stories, a joyous read for curious minds, making it an easy read for laymen and even school students.

The book is written from an engineering rather than a biological perspective and one may speculate about evolutionary and adaptive mechanisms while reading the book. Hu writes that "animal motion is all around us. It is the principal way animals get things done in the world. How did such a diversity of animal movements come about?" (p. 4), but the book does not tell us how these animals might have adapted and does not therefore generalize for other species.

Altogether, the book is for general readers interested in learning how scientific inquiry should work and how a scientist thinks and does experiments. That is a very interesting, fun, thought-provoking, story-based, and amusing book for undergraduate and high school students interested in physics, robotics, fluid mechanics, mechanical engineering, and related disciplines.

\section{Literature Cited}

Einstein, A. 1955. Old man's advice to youth: 'never lose a holy curiosity’. Life Magazine 1955 (May): 64.

FARID PAZHOOHI

Department of Psychology, University of British Columbia, Vancouver, BC, Canada 